\title{
$\Omega$
}

Ian Balfour-Lynn

D

Paediatric Respiratory Medicine, Royal Brompton Hospital, London, UK

\section{Oxford Respiratory Medicine Library: Cystic Fibrosis}

\author{
Editors: A. Horsley, S. Cunningham and J.A. Innes; \\ OUP Oxford; 208 pages; ISBN: 978-0-19-870294-8
}

\section{Book review}

This is a compact but comprehensive book on cystic fibrosis (CF). It is multi-authored and edited by three well-known cystic fibrosis doctors (two adult physicians and one paediatrician), so immediately I must declare a conflict of interest, in that I know many of the writers; not surprising within the relatively small field of CF. The book is pocket-sized so inevitably topics have to be brief, but there are no major areas that have been omitted. The person most likely to buy it is someone starting out in the field of CF who wants to get up to speed quickly. Additionally, it will be very useful for nurses and allied health professionals in contact with CF patients. Overall, it is a good book and I particularly like the key points at the start of each chapter.

While the book is good overall, there are some minor issues. First, the font is somewhat small and the illustrations are all black and white, both presumably to keep production costs down; while it is not always a problem, some of the more complex diagrams would have benefited from being in colour. There is one particular pneumothorax radiograph which I have scrutinized but can barely see the lung edge. There is a formulary at the back, which always makes me anxious in a book, but I doubt it will be used as a source for prescribing, due to local guidelines and the availability of online national formularies. Additionally, I thought that the dose section on ivacaftor should have made note of some of the important drug interactions that prescribers need to be aware of.

I have a few small specific criticisms. In one instance, the normal sweat chloride concentration is given as $<40 \mathrm{mmol} \cdot \mathrm{L}^{-1}$ but, generally 30 is considered to be the cut off, especially when used in newborn screening. The suggestion of measuring vitamin $\mathrm{K}$ at annual review is unusual; however, I am not aware of any assay in regular use outside of a research context. The section on non-tuberculous mycobacteria could have been a bit longer given its growing significance, and the section on allergic bronchopulmonary aspergillosis referred to in the index is also quite brief, although a more comprehensive (but non-indexed) section is available later in the book. Finally, given the speed of developments in the field, the chapter on future therapies is already out of date and will become even more so in another year.

Despite these few and minor complaints, this is a good book and I recommend it for those wanting to learn the essentials of cystic fibrosis.
Cite as: Balfour-Lynn I. Book review: Oxford Respiratory Medicine Library: Cystic Fibrosis. Breathe 2015; 11: 313.

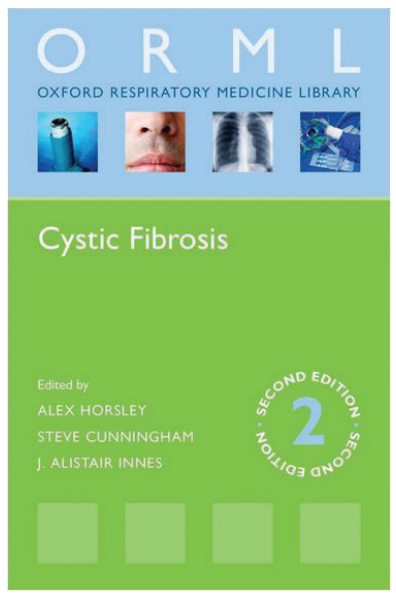

